\title{
Result of Combined Mifepriston and Misoprostol in Termination of Early Pregnancy at Different Gestational Age
}

\author{
Roy $\mathrm{M}^{1}$, Khan $\mathrm{R}^{2}$, Hasan $\mathrm{N}^{3}$, Karim $\mathrm{R}^{4}$, Nasrin $\mathrm{A}^{5}$, Rahman $\mathrm{N}^{6}$
}

\begin{abstract}
Introduction: An estimated 56 million induced abortion occured each year worldwide. Indirect estimates suggest more than 1.2 million annual menstrual regulations (MRs) and induce abortions each year in Bangladesh. Maternal mortality in Bangladesh is $1.76 / 1000$ live birth, one fourth of these deaths are due to complication of induced abortion. The safety of procedure is therefore of global public health importance. Now medical abortion option have made more available to women in a variety of health care setting and home administration of medical abortion is acceptable.
\end{abstract}

Objective: To know the outcome and safe use of mifepristone and misoprostol combination up to 9 weeks ( $<63$ days) of missed period to reduce the maternal morbidity, mortality related to complications of menstrual regulation (MR) and induced abortion in Bangladesh.

Materials and Methods: This was a prospective cross sectional study of outdoor patients (100 cases) of Marie Stopes Premium Maternity Hospital, Mirpur-10 who came for menstrual regulation within 9 weeks (63 days) of missed period by MRM (Menstrual Regulation by Medication), using $200 \mathrm{mg}$ of oral Mifepristone followed by buccal Misoprostol $800 \mu \mathrm{g}$. Study period was from July 2014 to December 2014.

Results: Success rates of regimen used in this study that are higher (98\%) in case of women $<6 \mathrm{wks}$ amenorrhoea than that group who have had amenorrhea up to 9 weeks $(94 \%)$. There were 4 failures $(4 \%)$, among them $1(2 \%)$ from women $<6$ weeks and $3(6 \%)$ from women $>6$ weeks who needed surgical evacuation later on.
Conclusion: MRM with Mifepristone 200mg followed by buccal Misoprostol $800 \mu \mathrm{g}$ is highly effective and safe.

Key-words: Medical abortion, Mifepristone, Misoprostol, Menstrual regulation by medication (MRM).

\section{Introduction}

Despite relatively high contraceptive prevalence $(61 \%)$ compared to other developing countries, Bangladesh continues to have low utilization of long term or permanent contraceptive methods, a high discontinuation rate ${ }^{1}$. Menstrual regulation has been part of Bangladesh's national family planning program since 1979. Indirect estimates suggest more than 1.2 million annual menstrual regulations (MRs) and induced abortions each year in Bangladesh ${ }^{2}$. Maternal mortality in Bangladesh is 1.76 /1000 live birth, one fourth of these deaths are due to complication of induce abortion.

An estimated 56 million induced abortion occured each year worldwide ${ }^{3}$. The safety of procedure is therefore of global public health importance. Now medical abortion options have made more available to women in a variety of health care setting and home administration of medical abortion is acceptable ${ }^{4}$. In the United States, about one fifth of all out patient abortions are performed medically ${ }^{5}$ and in several countries in Europe ${ }^{6}$, the proportion exceeds $60 \%$.

Medical abortion or MRM is the induction of early abortion by means of medications. It is a non surgical procedure in which drugs are used to induce abortion. Indication of medical abortion are when pregnancy continuation is harmful for maternal life

1. Maj Marlina Roy, MBBS, MCPS, DGO, FCPS, Classified Specialist (Obs and Gynae), CMH, Dhaka 2. Brig Gen Rokeya Khan, MBBS, MCPS, DGO, FCPS, Professor \& Head, Department of Obs and Gynae, AFMC, Dhaka 3. Maj Nasrin Hasan, MBBS, MCPS, FCPS, Classified Specialist (Obs and Gynae), CMH, Dhaka 4. Maj Rehnuma Karim, MBBS, FCPS, Classified Specialist (Obs and Gynae), CMH, Dhaka 5. Maj Alifa Nasrin, MBBS, DGO, MCPS, FCPS, Classified Specialist (Obs and Gynae), CMH, Dhaka 6. Dr Nahida Rahman, MBBS, Medical Officer, Marie Stopes Premium Maternity, Dhaka. 
or where child would be born with grave physical or mental defect, when women want to avoid surgical procedure for regulation of menstruation, women with uterine malformation or fibroid uterus or had cervical surgery where surgical abortion is technically difficult.

The most effective and safest medical abortion regimen requires the use of two medications: mifepristone and misoprostoll. The antiprogesterone mifepristone combined with the prostaglandin analogous (misoprostol) is effective for termination of early pregnancy and has a favorable safety profile $^{7}$. Early medical abortion regimens using $200 \mathrm{mg}$ oral mifepristone and $800 \mu \mathrm{g}$ misoprostol have been endorsed by Royal College of Obstetricians and Gynecologists (RCOG) as an effective and appropriate method of termination of pregnancy $^{8}$. Although medical abortion regimens approved by most government regulatory agencies specify $600 \mathrm{mg}$ mifepristone, in practice, a dose of $200 \mathrm{mg}$ is standard worldwide ${ }^{9}$.

A medical abortion is said to be successful when the medication used, achieves complete expulsion of the products of conception, without the need of any surgical intervention ${ }^{10}$. Medical terminations are safe and effective alternative to surgical vacuum aspiration of uterus with high level of patient satisfaction ${ }^{11}$. Medical abortion allows the women to avoid an invasive procedure and to avoid significant exposure to anesthetic medications. Many women feel medical abortion to be the more "natural" option, like a miscarriage, and prefer being in the comfort of their own home for the process ${ }^{12}$.

Mifepristone (RU486) is a potent anti-progestin but when it is administered alone for early pregnancy termination, it results in incomplete expulsion in approximately $20 \%$ of women ${ }^{13}$. This relative lack of efficacy may be due to an insufficient increase in prostaglandin concentration in uterus to allow completion of termination ${ }^{10}$. Administration of misoprostol after mifepristone, in different dosage schedules, has been found to be effective, feasible and acceptable method of medical termination in early pregnancy ${ }^{11}$. The regimen we used is similar to those recommended by the World Health Organization $(\mathrm{WHO})^{14}$. Research in communities reveals growing number of women who do not want to undergo invasive procedure such as MVA and seek abortificient drugs to establish normal menstruation ${ }^{15}$. A recent survey of Marie stopes Bangladesh in 62 pharmacies reveals that $51 \%$ of drug sellers and pharmacists know of drugs that can be used to induce medical abortion and 30 percent of drug stores and pharmacies sell these drugs to the public ${ }^{16}$. This study is to know the efficacy and safe use of medical MR in different gestational age up to 63 days $(<9 \mathrm{wks})$ and to reduce the maternal morbidity and mortality for complications of MR and induced abortion by implementation of MRM.

\section{Materials and Methods}

Subjects for this prospective randomized cross sectional study were enrolled from outdoor patients (100 cases) of Marie Stopes Premium Maternity Hospital, Mirpur-10, Dhaka-1216, who came for menstrual regulation within 9 weeks (63 days) of missed period by MRM (menstrual regulation by medication), using $200 \mathrm{mg}$ of oral mifepristone followed by buccal misoprostol $800 \mu \mathrm{g}$ from July 2014 to December 2014.

All subjects initially received $200 \mathrm{mg}$ of oral mifepristone and then were randomly assigned to receive buccal $800 \mu \mathrm{g}$ misoprostol at $24-36$ hours at health facility or at home. Some client chose self administration of second dose at home, they were given the misoprostol tablet, counsel on proper buccal technique, educated on possible side effects and informed of the safety procedure in case of an emergency. They were then followed up after 14 days with ultrasonography to confirm completion of expulsion. Treatment was considered failed if surgical evacuation was needed for any indication.

\section{Results}

Efficacy was analyzed in 100 women. Fifty percent $50 \%$ of them were $<6$ weeks ( 42 days) and $50 \%$ were between 6 weeks (43 days) to 9 weeks (63 days). Twelve patients were at 56 (8 weeks) days to 63 (9 weeks) days. Among women in whom treatment was successful, expulsion starts soon after the administration of misoprostol $70 \%$ in four hours and $30 \%$ within 24 hours in women $<6$ weeks of gestation and $62 \%$ in four hours and $38 \%$ within 24 hours in women $>6$ weeks of gestation (Table-I). 
Table-l: Time of first expulsion after administration of mifepriston and misoprostol $(n=100)$

\begin{tabular}{|c|c|c|c|c|c|}
\hline $\begin{array}{c}\text { Gestational } \\
\text { age }\end{array}$ & $\begin{array}{c}\text { Total no } \\
\text { of clients }\end{array}$ & $\begin{array}{c}\text { Within } \\
\text { 4 hours }\end{array}$ & $\mathbf{( \% )}$ & $\begin{array}{c}\mathbf{4 - 2 4} \\
\text { hours }\end{array}$ & $\mathbf{( \% )}$ \\
\hline$<6$ weeks & 50 & 35 & $70 \%$ & 15 & $30 \%$ \\
\hline$>6-9$ weeks & 50 & 31 & $62 \%$ & 19 & $38 \%$ \\
\hline
\end{tabular}

Table-II: Success rate of medical abortion at different gestational age in first trimester $(n=100)$

\begin{tabular}{|c|c|c|c|c|c|}
\hline Duration & $4-5 w k s$ & $5-6 w k s$ & $6-7 w k s$ & $7-8 w k s$ & $8-9 w k s$ \\
\hline $\begin{array}{c}\text { Total no of } \\
\text { clients (n=100) }\end{array}$ & 23 & 27 & 22 & 16 & 12 \\
\hline $\begin{array}{c}\text { Failure of } \\
\text { medical abortion }\end{array}$ & 0 & 1 & 1 & 1 & 1 \\
\hline Success rate & $100 \%$ & $96.24 \%$ & $95.45 \%$ & $93.75 \%$ & $91.66 \%$ \\
\hline
\end{tabular}

Table-II shows that there were 4 failures $(4 \%)$, among them $1(2 \%)$ from women $<6$ weeks and $3(6 \%)$ from women $>6$ weeks, all needs surgical evacuation. Overall success rate of medical abortion is $98 \%$ in $<6$ weeks and $94 \%$ in $>6-9$ weeks.

Table-III: Overall outcome of medical abortion $(n=100)$

\begin{tabular}{|c|c|c|c|c|}
\hline $\begin{array}{c}\text { Gestational } \\
\text { age }\end{array}$ & $\begin{array}{c}\text { Total no of } \\
\text { Clients(n=100) }\end{array}$ & $\begin{array}{c}\text { Failure of } \\
\text { medical } \\
\text { abortion }\end{array}$ & $\begin{array}{c}\text { Success } \\
\text { rate }\end{array}$ & $\begin{array}{c}\text { Failure } \\
\text { rate }\end{array}$ \\
\hline$<6 \mathrm{wks}$ & 50 & 1 & $98 \%$ & $2 \%$ \\
\hline$>6-9 \mathrm{wks}$ & 50 & 3 & $94 \%$ & $6 \%$ \\
\hline
\end{tabular}

All women had uterine bleeding, whatever the outcome of drug administration. The mean duration of bleeding is $8 \pm 2$ days in $<6$ weeks and $10 \pm 4$ days $>6$ weeks. No women received transfusion. Only one women (62 days of gestation) had slight vaginal spotting for 28 days. There were correlation between duration of amenorrhea and duration of bleeding. Most of the women $85 \%$ had uterine cramp, for which $20 \%$ received analgesic drugs. The pain usually started within one hour after taking of misoprostol and it lasted few hours or less. Nausia, diarrhoea and vomiting within four hours of administrating misoprostol in approximately $45 \%, 12 \%$ and $16 \%$ of the women respectively. One woman had vasovagal reaction secondary to painful uterine cramps.

\section{Discussion}

Medical abortion using mifepristone $200 \mathrm{mg}$ followed by $800 \mu \mathrm{g}$ misoprostol in the first 63 days of gestation is remarkably effective and safe ${ }^{17}$. Policy on MRM formulated as a strategic option for expanding safe MR services in Bangladesh ${ }^{18}$ in 2011. Mifepristone and misoprostol are the drugs increasingly used by WHO and licensed in about 150 countiers $^{19}$. These drugs are convenient than MR, because it is given orally with good good compliances. These drugs are inexpensive and can be stored at room temperature. The regimen used in this study appears to result in success rates that are higher $(98 \%)$ in case of women $<42$ days gestation than that group who have had amenorrhea up to 63 days (94\%) which is almost similar $(95.7 \%)$ to a study in Bangladesh ${ }^{20}$ and a study in Australia $^{21}$ where the success rate is $96.5 \%$. Intensity of uterine cramps after administration of misoprostolis comparatively more in women who had amenorrhea more than 42 days. The apparent decrease in the duration of bleeding in the women $<6$ weeks of gestation is encouraging.

In this study, no infection was reported. Infection following medical termination of pregnancy is reported to occur in $0.02 \%-0.92 \%$ of cases ${ }^{23}$. Death resulting from infection and fatal toxic shock after medical abortion with mifepristone is a known, but very rare ${ }^{24}$, risk $(1.1 / 1000,000)$. Although the Royal College of Obstetricians and gynecologists (RCOG) recommends universal prophylactic antibiotics effective against $C$. trachomatis and anaerobes to reduce infection after medical abortion, the $\mathrm{WHO}^{14}$ does not. The sides effects of two drugs neither more frequent nor more severe but slightly higher in women $>6$ weeks of amenorrhoea. Regarding side effects mifepristone did not give any serious side effects. Few clients had nausea, vomiting and diarrhoea within of two drugs neither more frequent nor more severe but slightly higher in women $>6$ weeks of pregnancy.

However, caution should be exercised in using this agent in women at risk for cardiovascular accidents. This study also found higher risk of medical abortion failure rates that had a high proportion in $>42$ days of gestation $(6 \%)$ and it is $4 \%$ higher than those gestational age $<42$ days which are almost similar to other studies ${ }^{20-22}$. However higher risk of ongoing pregnancy in these group did not found. Overall risk of medical abortion failure in both groups seems reasonable. Moreover, prompt confirmation of completeness of the abortion by clinical assessment and routine ultrasound may enhance women's satisfaction with the procedure. This study observed no evidence that allowing women to take misoprostol at home increased abortion failure rate or serious complications. Most women preferred this option and 
it is presumably substantially more efficient for the health care system than requiring patients to return to the provider for administration of the prostaglandin ${ }^{17}$.

\section{Conclusion}

In the study reported here that for the termination of pregnancy, in women who had amenorrhea for less than 42 days ( $<6$ weeks) is more successful as well as well tolerated than women had pregnancy between 43 days ( $>6$ weeks) to 63 days (9 weeks). In spite of satisfactory results reported here, we wish to emphasize that the abortion procedure should continue to be medically supervised.

\section{References}

1. Bangladesh Demographic and Health Suevey 2011, Dhaka, Bangladesh and Calverton, Maryland, USA: NIPORT, Mitra and Associates and ICF International.

2. Singh et al."The incidence of menstrual regulation procedure and abortion in Bangladesh" International prespective on sexual and reproductive health 2012; 38(3):122-32.

3. Sedgh G, Bearak J, Singh S et al. Abortion incidence between 1990 and 2014: global, regional, and subregional levels and trends. Lancet 2016 Jul 16; 388(10041):258-67.

4. Kopp Kallner H, Fiala C, Gemzell-Danielsson K. Assesment of significant factors affecting accept-ability of home administration of misoprostol for medical abortion. Contraception 28 Sep 2011; 85(4):394-7.

5.Jones RK, Kooistra K. Abortion incidence and access to services in the United States, 2008; perspective Sex Record Health $2011 ; 43: 41-50$.

6. Niinimaki M, Pouta A, Bloigu A et al. Immideate complications after medical compared with surgical termination of pregnancy. ObstetGynecol 2009; 114:795-804.

7. Flala C, Gemzel-Danielsson K. Review of medical abortion using mifepristone in combination with a prostadland in analogue. Contraception 2006; 74:66-86.

8. Royal College of Obstetrics and Gynaecologists. Evidence-based clinical guideline number 7. London: RCOG 2011. http://www.rcog.org.uk/files/rcog-corp/.

9. Sivin I, Trussell J, Lichtenberg ES et al. Unexpected heaping in reported gestational age for women undergoing medical abortion. Contraception 2009; 80:287-91.

10. ACOG practice bulletin. Clinical management guidelines of obstetrician-gynecologists. Number 67, October 2005. Medical management of abortion. Obstet Gynecol 2005; 106:871-82 .
11. Winikoff B, Sivin I, Coyaji KJ et al. Safety, efficacy and acceptability of medical abortion in China, Cuba and India: A comparative trial of mifepristone-misoprostol versus surgical abortion. Am J Obstet Gynecol 1997; 176:431-7.

12. Slade $P$, Heke $S$. Fletcher $J$ et al. A comparison of medical and surgical termination of pregnancy: Choice, emotional impact and satisfaction with care. BJOGInt J Obstet Gynaecol 1998; 105:1288-95.

13. Kulier R, Gülmezoglu AM, Hofmeyr GJ et al. Medical methods for first trimester abortion. Cochrane Database Syst Rev 2004; 2:CD002855.

14. World Health Organization. Safe abortion: Technical and policy guidance for health system. 2nd ed. Geneva: WHO 2012.

15. Piet-Pelon, Nancy, Rob U. "Menstrual regulation past, Present and Future Challenge" Polisy Diagalogue. Dhaka Bangladesh Population Council 1999.

16. Rasul, Golam K. "Know your market; Short field survey on pharmacy" Dhaka Bangladesh; Marie Stopes Bangladesh 2009 .

17. Elizabeth G, Raymond, Caitlin Shannon et al. First trimester medical abortion with mifepristone $200 \mathrm{mg}$ and misoprostol: A systemic review, 14 August 2012.

18. Shahidullah SM (Country Director, IPAS Bangladesh). Introducing MRM in Bangladesgh and Future challenges; 24 May 2015.

19. Safty, efficacy and acceptability of medical abortion with mifepristone and misoprostol in Nepalese women. $\mathrm{NJ}$ Obstet Gynaecol 2007 Nov-Dec; 2(2):54-8.

20. Hena I, Rob U, Nargis Sultana $N$ et al. Introducing Medical MR in Bangladesh, MRM Final Report. Jan 2014.

21. Early medical abortion using low dose mifepristone followed by buccalmisoprostal: A large Australian observational study. Philip goldstone, Jill Michelson, Eva Williamson, MJA 2012; 197:282-6.

22. Raymond EG, Shannon C, Weaver MA et al. FirstTrimester medical abortion with mifepristone $200 \mathrm{mg}$ and misoprostol: Asystemic review. Contraception 2013 Jan; 87(1):26-37.

23. Shannon C, Brothers LP, Philip NM et al. Infection after medical abortion: A review of the literature. Contraception 2004; 70:183-90

24. Henderson JT, Hwang AC, Harper CC et al. Safty of mifepristone abortions in clinical use. Contraception 2005; 72:175-8. 